\title{
An EGFR T790M-mutated lung adenocarcinoma undergoing large-cell neuroendocrine carcinoma transformation after osimertinib therapy: a case report
}

\author{
Shinichi Miyazaki ${ }^{*}$, Yasumasa Kuno ${ }^{1}$, Shunsaku Hayai ${ }^{1}$, Ryo Teramachi ${ }^{2}$, Ryo Yamashita', Yusuke Saito ${ }^{3}$,
} Kosuke Higuchi ${ }^{3}$, Yoshiharu Nara ${ }^{4}$ and Takuya Ikeda ${ }^{1}$

\begin{abstract}
Background: Osimertinib, a third-generation epidermal growth factor receptor tyrosine kinase inhibitor, is selective for both epidermal growth factor receptor tyrosine kinase inhibitor-sensitizing and T790M resistance mutations. Almost all patients who initially respond to an epidermal growth factor receptor tyrosine kinase inhibitor subsequently report disease progression. Epidermal growth factor receptor-dependent resistance mechanisms, bypass pathway activation, and histological transformation have been reported with osimertinib therapy.

Case presentation: We report a case of a 64-year-old Asian man with epidermal growth factor receptor T790Mpositive adenocarcinoma that transformed to epidermal growth factor receptor T790M-negative large-cell neuroendocrine carcinoma after osimertinib therapy. A prompt rebiopsy revealed a rare mechanism of resistance to epidermal growth factor receptor tyrosine kinase inhibitor, and subsequently treatment with carboplatin and etoposide was effective.
\end{abstract}

Conclusions: Despite the promising emergence of circulating tumoral DNA testing, this case report emphasizes the importance of rebiopsy of a progressive epidermal growth factor receptor-mutant tumor.

Keywords: Epidermal growth factor receptor, T790M, Osimertinib, Large-cell neuroendocrine carcinoma, Transformation

\section{Background}

Lung cancer is the most common cause of cancer mortality worldwide. Non-small-cell lung cancer (NSCLC) accounts for $85 \%$ of cases and includes adenocarcinoma, squamous cell carcinoma, and large-cell carcinoma. The epidermal growth factor receptor (EGFR) gene is one of the most important oncogenes in NSCLC. Mutations in EGFR tyrosine kinase are observed in $51.4 \%$ of advanced

\footnotetext{
*Correspondence: miyazaki.sin1@gmail.com

'Department of Respiratory Medicine, Yokkaichi Municipal Hospital, 2-2-37, Shibata, Yokkaichi-shi, Mie 510-0822, Japan

Full list of author information is available at the end of the article
}

NSCLC adenocarcinoma cases in Asian populations compared, with approximately $20 \%$ among the white population [1]. EGFR mutations are more common in nonsmokers and women. Osimertinib therapy is the first-line treatment for patients with metastatic NSCLC whose tumors have EGFR exon 19 deletions or exon 21 L858R mutations. It is also effective against tumors that harbor the T790M EGFR mutation responsible for 50\% of acquired resistance to first- and second-generation EGFR tyrosine kinase inhibitors (TKIs) [2]. Almost all patients who initially respond to an EGFR TKI subsequently report disease progression. EGFR-dependent

(c) The Author(s). 2020 Open Access This article is licensed under a Creative Commons Attribution 4.0 International License, which permits use, sharing, adaptation, distribution and reproduction in any medium or format, as long as you give appropriate credit to the original author(s) and the source, provide a link to the Creative Commons licence, and indicate if changes were made. The images or other third party material in this article are included in the article's Creative Commons licence, unless indicated otherwise in a credit line to the material. If material is not included in the article's Creative Commons licence and your intended use is not permitted by statutory regulation or exceeds the permitted use, you will need to obtain permission directly from the copyright holder. To view a copy of this licence, visit http://creativecommons.org/licenses/by/4.0/ The Creative Commons Public Domain Dedication waiver (http://creativecommons.org/publicdomain/zero/1.0/) applies to the data made available in this article, unless otherwise stated in a credit line to the data. 
resistance mechanisms (such as the C797S point mutation), bypass pathway activation (such as mesenchymalepithelial transition factor amplification), and histological transformation (such as small cell carcinoma) have been reported with osimertinib therapy [3]. We report a rare case of a patient in whom EGFR T790Mpositive adenocarcinoma transformed into large-cell neuroendocrine carcinoma (LCNEC) after osimertinib therapy.

\section{Case presentation}

A 64-year-old Asian man with a 46-pack-year smoking history was referred to our department for progressive exertional dyspnea over the course of 1 week. An extensive workup demonstrated a right middle lobe mass, right hilar lymphadenopathy, bilateral pulmonary nodules, and right pleural effusion with pleural nodules, as well as nodules in the peritoneum, mesentery, and omentum (Fig. 1). Histopathological and molecular analyses of transbronchial biopsy specimens from the right middle lobe revealed adenocarcinoma; the malignant epithelial cells were positive for carcinoembryonic antigen (CEA) and negative for synaptophysin (Fig. 2), and they harbored an exon 19 deletion mutation in EGFR. The patient was initially treated with afatinib, which resulted in a partial response.

Seventeen months later, computed tomography $(\mathrm{CT})$ revealed progression of the primary lesion in the right middle lobe and new metastasis to the right pleura. Five cycles of carboplatin (CBDCA) and pemetrexed (PEM) were administered as second-line treatment, which subsequently stabilized the disease. Although one cycle of maintenance therapy with PEM was administered, the lesions of the right middle lobe and pleura progressed. Over the next 7 months, neither six cycles of docetaxel treatment nor afatinib rechallenge was effective. A liquid biopsy revealed EGFR-T790M mutation, and the patient received osimertinib therapy. Although this maintained the stable disease status for 4 months, rapid progression of the right pleural metastasis occurred subsequently. A CT-guided biopsy of the pleura was performed, and LCNEC characterized by positive CEA and synaptophysin staining was identified by histologic examination (Fig. 2). Molecular analysis revealed the EGFR exon 19 deletion without T790M mutation. Thus, a combination of CBDCA and etoposide (VP-16) was initiated, and the patient had stable disease for 3 months. After three cycles of CBDCA and VP-16, the right pleural metastasis progressed, and the treatment was changed to amrubicin (AMR). After one cycle of AMR, he developed superior vena cava syndrome, and he died 41 months after the initial presentation.

\section{Discussion}

We report a case of a patient with EGFR T790Mpositive adenocarcinoma that transformed to EGFR T790M-negative LCNEC after osimertinib therapy. EGFR exon 19 deletion was identified in both the adenocarcinoma and LCNEC. To the best of our knowledge, this is the fourth description of adenocarcinoma transformation to LCNEC after osimertinib therapy [4-6]. One recent study investigating the mechanisms of resistance to osimertinib in 73 consecutive patients reported only small cell lung cancer (SCLC) transformation in 4

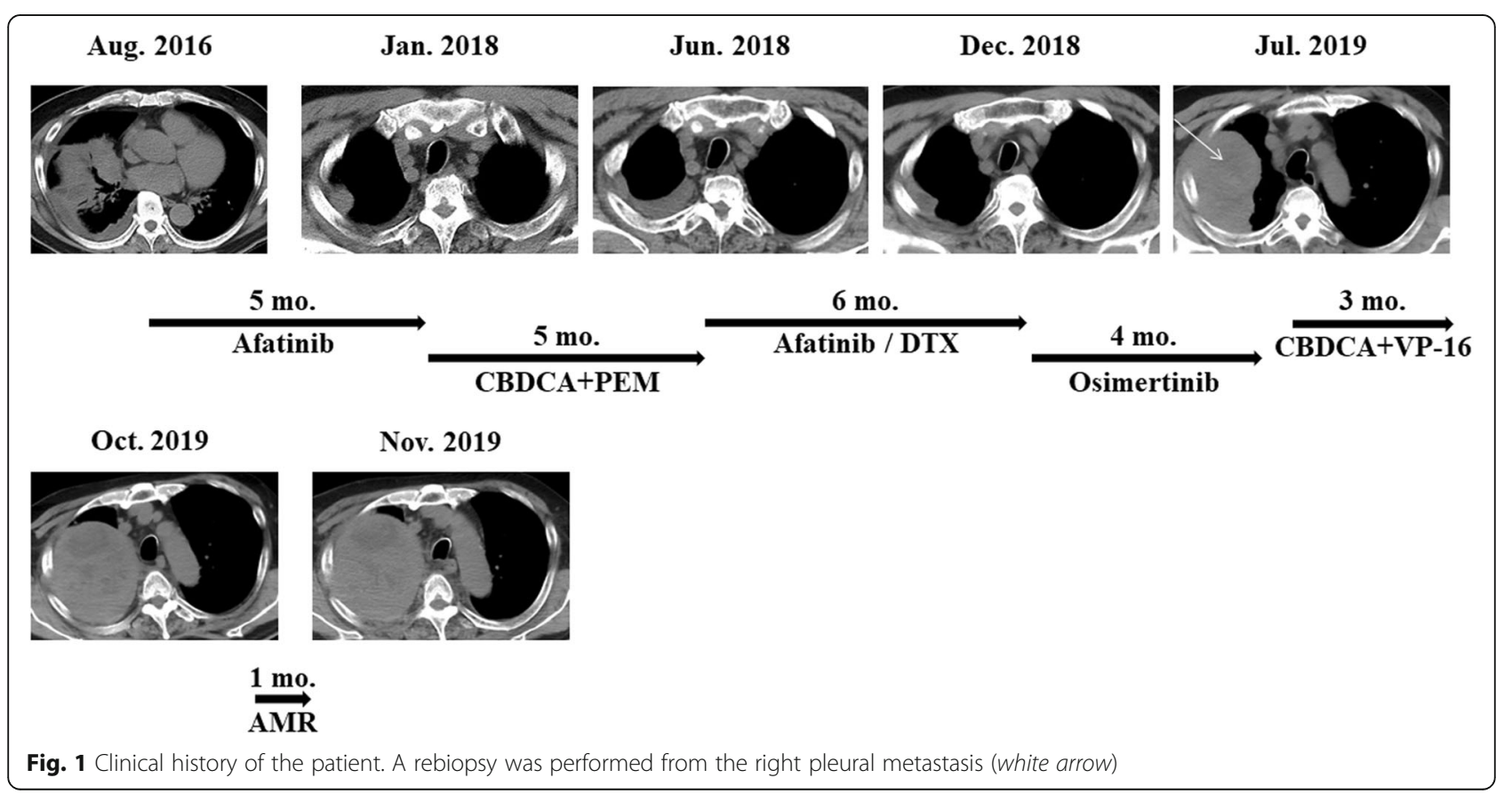




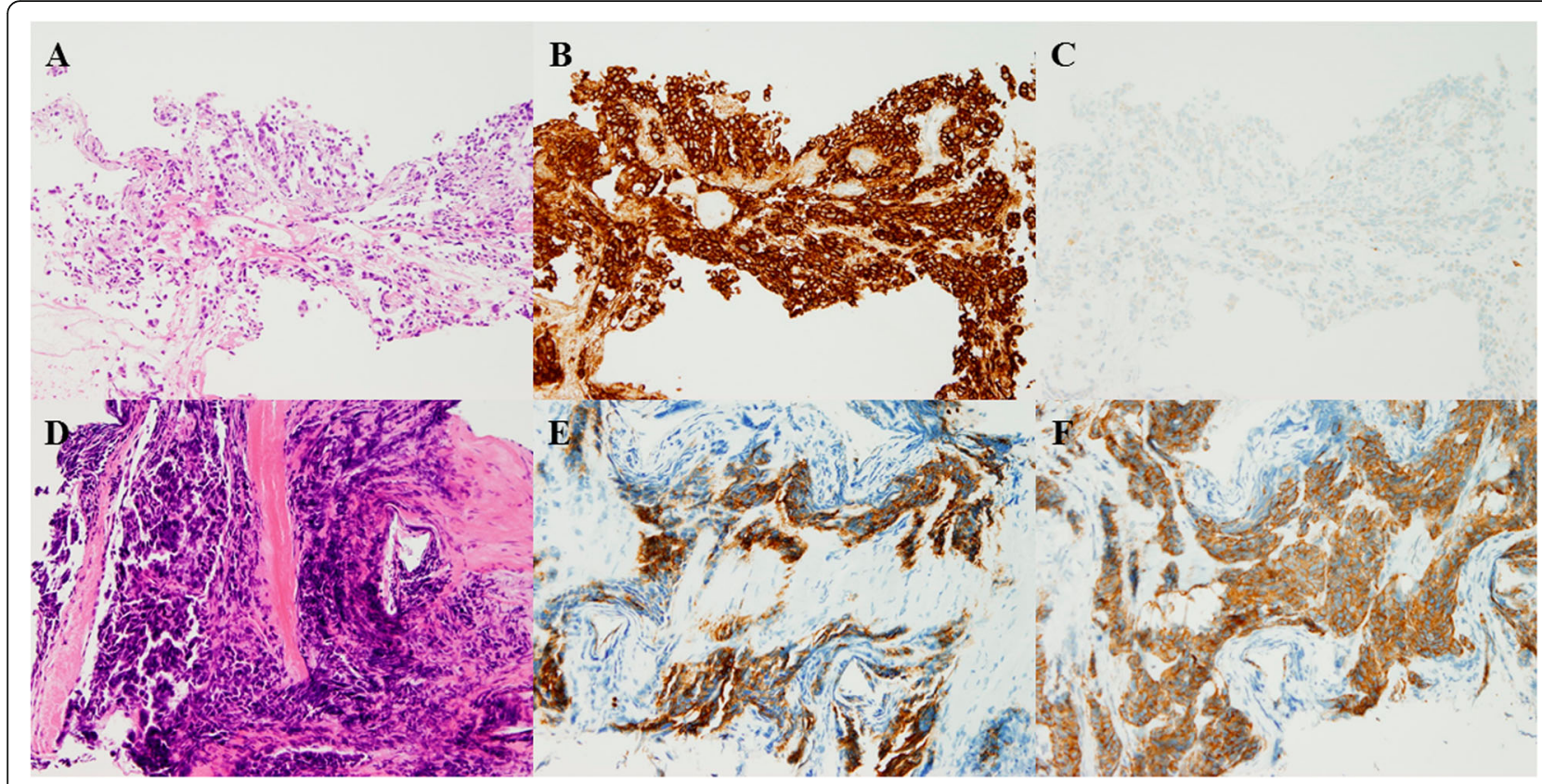

Fig. 2 a-c Histopathological results of the biopsy specimen. a Hematoxylin and eosin staining. b Carcinoembryonic antigen staining (CEA). c Synaptophysin staining. Original magnification, $\times 100$. $\mathbf{d}-\mathbf{f}$ Histology of pleural biopsy specimen. $\mathbf{d}$ Hematoxylin and eosin staining. e CEA staining. $\mathbf{f}$ synaptophysin staining. Original magnification, $\times 100$

patients [7]. LCNEC shares several clinical characteristics and genomic features with SCLC [8], and, similarly to cases of adenocarcinoma transforming to SCLC [9], the underlying mechanism leading to neuroendocrine differentiation may be the inactivation of retinoblastoma 1 (RB1) and tumor protein 53 (TP53). Inactivation of RB1 and TP53 was observed in pretransformed and post-transformed EGFR-mutant lung adenocarcinoma [9]. However, RB1 loss alone is not sufficient to drive SCLC transformation [10], indicating that other changes must occur in tumors to promote SCLC transformation. The preferential APOBEC (apolipoprotein B mRNA editing enzyme catalytic polypeptide-like)-induced hypermutation was observed in transformed SCLCs, whereas EGFR T790M-positive lung adenocarcinoma had rare APOBEC-associated mutations. The APOBEC mutational process may induce SCLC transformation through genomic instability.

Several demographic and pathological factors are associated with EGFR mutation prevalence. EGFR mutations tend to be more common among patients with an adenocarcinoma histology and among nonsmokers [11]. Among Asian populations, the average incidences of EGFR mutations were $31 \%$ overall, $47 \%$ among patients with adenocarcinoma, and 56\% among nonsmokers. Among white populations, the average incidences of EGFR mutations were $7 \%$ overall, $13 \%$ among patients with adenocarcinoma, and 35\% among nonsmokers. The reason for the high frequency of EGFR mutations in
Asian patients is unclear, and genome-wide association studies may identify loci that are specifically related to EGFR-targeted carcinogenesis [12]. A multicenter phase II study on cisplatin-etoposide chemotherapy for LCNE $\mathrm{C}$ demonstrated that the major efficacy endpoints were similar to those of SCLC [13], and researchers have recommended platinum-etoposide chemotherapy treatment [14]. In 2018, Horn et al. reported that the addition of atezolizumab to chemotherapy in the first-line treatment of extensive stage SCLC increased overall survival and progression-free survival significantly compared with chemotherapy alone [15]. These data suggest that adding an immune checkpoint inhibitor to etoposide-platinum in the front-line setting improves prognosis for patients with LCNEC. At the time we treated our patient, however, addition of atezolizumab to chemotherapy was not approved, owing to the restrictions of the national health insurance system in Japan.

Although rebiopsy has a pivotal role in investigating mechanisms of resistance to EGFR TKIs, it is not always feasible. Previous studies have reported that the rate of rebiopsy is approximately $50 \%[16,17]$; the reasons for not performing a rebiopsy were inaccessible tumors $(5 \%)$, deterioration in performance status (4\%), and patient refusal (22\%) [18]. In the present study, rebiopsy revealed that transformation to LCNE $C$ was the mechanism underlying the resistance to EGFR TKI and subsequently led to effective treatment of our patient (Fig. 3). 


\section{Advanced EGFR-mutant NSCLC patients} Osimertinib

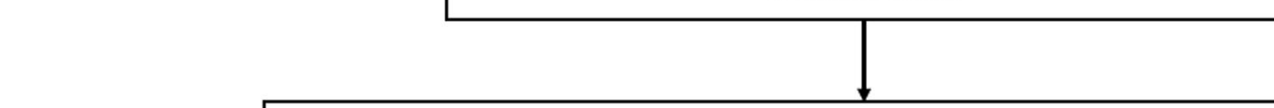

Compared with the clinical course so far, rapid disease progression?

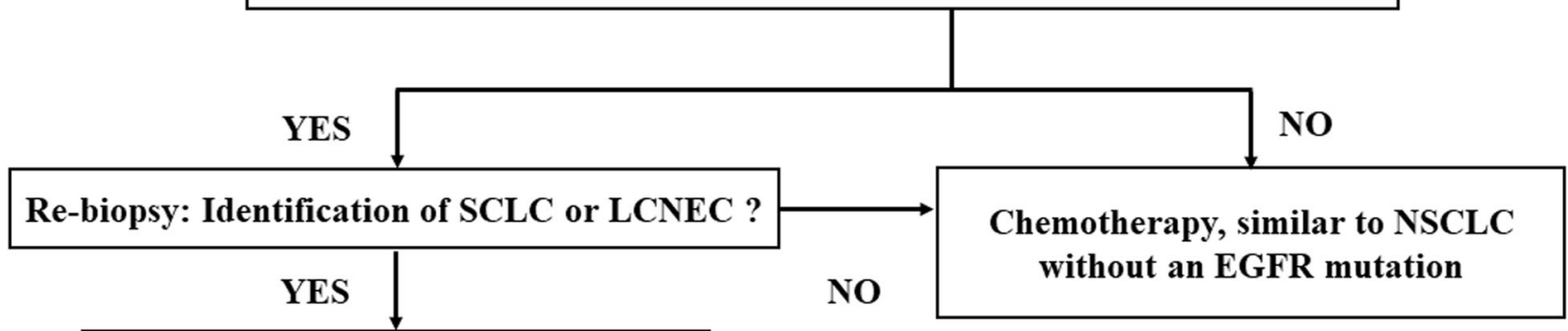

Chemotherapy, similar to SCLC

Fig. 3 Treatment algorism for advanced epidermal growth factor receptor-mutant patients with non-small-cell lung cancer

\section{Conclusions}

We report a case of a patient in whom EGFR T790Mpositive adenocarcinoma transformed into LCNEC after osimertinib therapy. Rebiopsy of the tumor after disease progression was instrumental in determining the mechanism of osimertinib resistance and led to effective treatment.

\section{Abbreviations \\ AMR: Amrubicin; APOBEC: Apolipoprotein B mRNA editing enzyme catalytic polypeptide-like; CBDCA: Carboplatin; CEA: Carcinoembryonic antigen; $C T$ : Computed tomography; EGFR: Epidermal growth factor receptor; LCNE C: Large-cell neuroendocrine carcinoma; NSCLC: Non-small-cell lung cancer; PEM: Pemetrexed; RB1: Retinoblastoma 1; SCLC: Small cell lung cancer; TKI: Tyrosine kinase inhibitor; TP53: Tumor protein 53; VP-16: Etoposide}

\section{Acknowledgements}

Not applicable.

\section{Authors' contributions}

SM cared for the patient, performed the clinical reasoning, and wrote the article. YK, SH, RT, RY, and TI cared for the patient. YN made the pathological diagnosis and contributed microscopic pictures. YS and KH helped in preparing the manuscript. All authors read and approved the final manuscript.

\section{Funding}

There was no funding for this case report.

\section{Availability of data and materials}

Data are available from the corresponding author on reasonable request.

\section{Ethics approval and consent to participate}

Not applicable.

\section{Consent for publication}

Written informed consent was obtained from the patient for publication of this case report and any accompanying images. A copy of the written consent is available for review by the Editor-in-Chief of this journal.

\section{Competing interests}

None declared.

\section{Author details}

${ }^{1}$ Department of Respiratory Medicine, Yokkaichi Municipal Hospital, 2-2-37, Shibata, Yokkaichi-shi, Mie 510-0822, Japan. ${ }^{2}$ Department of Respiratory Medicine, Nagoya University Graduate School of Medicine, 65 Tsurumai-cho, Showa-ku, Nagoya 466-8560, Japan. ${ }^{3}$ Department of Pharmacy, Yokkaichi Municipal Hospital, 2-2-37, Shibata, Yokkaichi-shi, Mie 510-0822, Japan. ${ }^{4}$ Department of Pathology, Yokkaichi Municipal Hospital, 2-2-37, Shibata, Yokkaichi-shi, Mie 510-0822, Japan.

Received: 25 November 2019 Accepted: 6 July 2020

Published online: 07 August 2020

\section{References}

1. Shi Y, Au JS, Thongprasert S, et al. A prospective, molecular epidemiology study of EGFR mutations in Asian patients with advanced non-small-cell lung cancer of adenocarcinoma histology (PIONEER). J Thorac Oncol. 2014;9: $154-62$.

2. Jänne PA, Yang JC, Kim DW, et al. AZD9291 in EGFR inhibitor-resistant nonsmall-cell lung cancer. N Engl J Med. 2015;372:1689-99.

3. Minari R, Bordi P, Tiseo M. Third-generation epidermal growth factor receptor-tyrosine kinase inhibitors in T790M-positive non-small cell lung cancer: review on emerged mechanisms of resistance. Transl Lung Cancer Res. 2016;5:695-708.

4. Ricordel C, Llamas-Gutierrez F, Chiforeanu D, et al. Large cell neuroendocrine lung carcinoma transformation as an acquired resistance mechanism to osimertinib. J Thorac Oncol. 2017;12:e184-6.

5. Baglivo S, Ludovini V, Sidoni A, et al. Large cell neuroendocrine carcinoma transformation and EGFR-T790M mutation as coexisting mechanisms of acquired resistance to EGFR-TKls in lung cancer. Mayo Clin Proc. 2017;92: 1304-11.

6. Moriguchi S, Uruga H, Fujii T, et al. Transformation of epidermal growth factor receptor T790M mutation-positive adenosquamous carcinoma of the ung to small cell carcinoma and large-cell neuroendocrine carcinoma following osimertinib therapy: an autopsy case report. Respirol Case Rep. 2019:7:e00402

7. Mehlman C, Cadranel J, Rousseau-Bussac G, et al. Resistance mechanisms to osimertinib in EGFR-mutated advanced non-small-cell lung cancer: a multicentric retrospective French study. Lung Cancer. 2019;137:149-56.

8. Miyoshi T, Umemura S, Matsumura Y, et al. Genomic profiling of large-cell neuroendocrine carcinoma of the lung. Clin Cancer Res. 2017;23:757-65. 
9. Lee JK, Lee J, Kim S, et al. Clonal history and genetic predictors of transformation into small-cell carcinomas from lung adenocarcinomas. J Clin Oncol. 2017;35:3065-74.

10. Niederst MJ, Sequist LV, Poirier JT, et al. RB loss in resistant EGFR mutant lung adenocarcinomas that transform to small-cell lung cancer. Nat Commun. 2015;6:6377.

11. Sekine I, Yamamoto N, Nishio K, et al. Emerging ethnic differences in lung cancer therapy. Br J Cancer. 2008;99:1757-62.

12. Mitsudomi T. Molecular epidemiology of lung cancer and geographic variations with special reference to EGFR mutations. Transl Lung Cancer Res. 2014;3:205-11.

13. Le Treut J, Sault MC, Lena H, et al. Multicentre phase II study of cisplatinetoposide chemotherapy for advanced large-cell neuroendocrine lung carcinoma: the GFPC 0302 study. Ann Oncol. 2013;24:1548-52.

14. Derks JL, van Suylen RJ, Thunnissen E, et al. Chemotherapy for pulmonary large cell neuroendocrine carcinomas: does the regimen matter? Eur Respir J. 2017:49:1601838.

15. Horn L, Mansfield AS, Szczęsna A, et al. First-line atezolizumab plus chemotherapy in extensive-stage small-cell lung cancer. N Engl J Med. 2018;379:2220-9.

16. Kawamura T, Kenmotsu H, Taira T, et al. Rebiopsy for patients with nonsmall-cell lung cancer after epidermal growth factor receptor-tyrosine kinase inhibitor failure. Cancer Sci. 2016;107:1001-5.

17. Ichihara E, Hotta K, Kubo T, et al. Clinical significance of repeat rebiopsy in detecting the EGFR T790M secondary mutation in patients with non-small cell lung cancer. Oncotarget. 2018;9:29525-31.

18. Zhou J, Zhao C, Zhao J, et al. Re-biopsy and liquid biopsy for patients with non-small cell lung cancer after EGFR-tyrosine kinase inhibitor failure. Thorac Cancer. 2019;10:957-65.

\section{Publisher's Note}

Springer Nature remains neutral with regard to jurisdictional claims in published maps and institutional affiliations.

Ready to submit your research? Choose BMC and benefit from:

- fast, convenient online submission

- thorough peer review by experienced researchers in your field

- rapid publication on acceptance

- support for research data, including large and complex data types

- gold Open Access which fosters wider collaboration and increased citations

- maximum visibility for your research: over $100 \mathrm{M}$ website views per year

At $\mathrm{BMC}$, research is always in progress.

Learn more biomedcentral.com/submissions 